Revista Eletrônica do Mestrado em Educação Ambienta1

Programa de Pós-Graduação em Educação Ambienta1

\title{
A Educomunicação na perspectiva da pedagogia ambiental: construindo um ecossistema comunicativo entre escola e comunidade ${ }^{1}$
}

Jonielton Oliveira Dantas ${ }^{2}$

Universidade Federal de Sergipe https://orcid.org/0000-0003-1196-9266

\author{
Maria José Nascimento Soares ${ }^{3}$ \\ Universidade Federal de Sergipe \\ https://orcid.org/0000-0001-7879-4769 \\ Marília Barbosa dos Santos ${ }^{4}$ \\ Universidade Federal de Sergipe \\ https://orcid.org/0000-0001-5310-4266
}

Resumo: A educomunicação busca melhorar o nível de comunicação das ações educativas, visando a criação e fortalecimento de ecossistemas comunicativos. Um campo consolidado, porém aberto a novas contribuições. Neste sentido, o presente artigo tem como objetivo descrever a educomunicação como estratégia de socialização dos saberes ambientais construídos mediante relação entre escola e comunidade, inserida em um processo mais amplo e sistêmico na pedagogia ambiental. Trata-se de uma pesquisa do tipo bibliográfica, tendo como fonte livros e artigos científicos. Considera-se que a construção de um ecossistema comunicativo por meio da educomunicação na perspectiva da pedagogia ambiental pressupõe uma gestão da comunicação nos espaços educativos baseada nos seguintes procedimentos: planejamento das ações, participação, comunicação educativa processual, capacidade de expressão e avaliação do processo educomunicativo.

Palavras-chave: Educomunicação. Pedagogia Ambiental. Comunidade escolar. Ecossistema comunicativo.

\footnotetext{
${ }^{1}$ Agência de fomento: Coordenação de Aperfeiçoamento de Pessoal de Nível Superior - Brasil (CAPES)

2 Aluno do Doutorado em Desenvolvimento e Meio Ambiente-PRODEMA/UFS; Mestre em Desenvolvimento e Meio Ambiente-PRODEMA. e-mail: jonielton.dantas@ gmail.com

${ }^{3}$ Doutorado em Educação pela Universidade Federal do Rio Grande do Norte; Mestrado em Educação pela Universidade Federal de Sergipe. e-mail: marjonasos@gmail.com

${ }^{4}$ Aluna do Doutorado em Desenvolvimento e Meio Ambiente-PRODEMA/UFS; Mestre em Desenvolvimento e Meio Ambiente-PRODEMA. e-mail: maryliabsantos@ hotmail.com
} 


\title{
Educomunicación en la perspectiva de la pedagogía ambiental: construir un ecosistema comunicativo entre la escuela y la comunidad
}

Resumen: La educomunicación intenta mejorar el nivel de comunicación en las acciones educativas, con el objetivo de crear y fortalecer ecosistemas comunicativos. Un campo consolidado, pero abierto a nuevas contribuciones. En este sentido, este artículo tiene como objetivo describir la educomunicación como una estrategia de socialización de los saberes ambientales construidos a través de la relación entre la escuela y la comunidad, agregada en un proceso más amplio y sistémico en la pedagogía ambiental. Tratase de una investigación bibliográfica, que tiene como fuente libros y artículos científicos. Se considera que la construcción de un ecosistema comunicativo a través de la educomunicación desde la perspectiva de la pedagogía ambiental presupone una gestión de la comunicación en los espacios educativos basada en los siguientes procedimientos: planificación de las acciones, participación, comunicación educativa procesal, capacidad de expresión y evaluación del proceso educomunicativo.

Palabras clave: Educomunicación. Pedagogía Ambiental. Comunidad escolar. Ecosistema comunicativo.

\section{Educomunication in the perspective of environmental pedagogy: building a communicative ecosystem between school and community}

\begin{abstract}
Educommunication seeks to improve the communication level of educational actions, aiming at the creation and strengthening of communicative ecosystems. A consolidated field, but open to new contributions. In this sense, this article aims to describe educommunication as a strategy of socialization of environmental knowledge built through the relationship between school and community, inserted in a broader and systemic process in environmental pedagogy. It is a bibliographic research, having as source books and scientific articles. It is considered that the construction of a communicative ecosystem through educommunication from the perspective of environmental pedagogy presupposes a management of communication in educational spaces based on the following procedures: action planning, participation, procedural educational communication, capacity for expression and evaluation of the educommunicative process.
\end{abstract}

Keywords: Educommunication. Environmental Pedagogy. School community. Communicative ecosystem.

\section{Introdução}

A inter-relação do campo da Educação com o campo da Comunicação, vem se configurando nas últimas décadas em um novo aporte teórico-prático: a educomunicação. Vale lembrar que tanto a educação quanto a comunicação, dentro da racionalidade moderna, tiveram seus campos de atuação bem delimitados no imaginário social, definidas em campos isolados, cumprindo funções distintas: “[...] a educação administrando a transmissão do saber necessário ao desenvolvimento social e a comunicação responsabilizando-se pela difusão das informações, pelo lazer popular e pela manutenção do sistema produtivo através da publicidade" (SOARES, 2000, p. 13). 
Neste sentido, a especialização dos saberes não é uma problemática circunscrita apenas na produção do conhecimento científico, tendo forte repercussão nos processos de formação docente, nas propostas pedagógicas de ensino, e na socialização com os demais agentes da comunidade escolar. Assim, a especialização do conhecimento científico em campos do saber, desencadeia processos de isolamento, seja do pesquisador em seu campo de estudo, do professor em seu campo disciplinar, e da escola em sua área de atuação ao desconsiderar a comunidade na qual está inserida.

É neste mote que a pedagogia ambiental está sendo construída, com a motivação de repensar os paradigmas de construção e socialização do conhecimento na perspectiva da complexidade e da interdisciplinaridade, e transformar os processos de transmissão e apreensão de conteúdos em processos dialógicos de saberes que considerem o ambiente, a cultura e a história de cada sujeito como possibilidade de apreender o mundo (LEFF, 2006; FREIRE, 2002).

Diante das demandas contemporâneas da sociedade, entre as quais a conservação do meio ambiente, a escola é chamada a desempenhar um trabalho de formação de uma consciência ambiental, que visa transformar a sociedade e transformar a si mesma, mediante desenvolvimento de uma proposta pedagógica que priorize uma abordagem sócio-política das questões socioambientais (PENTEADO, 2007). Este processo favorecerá um intercâmbio de conhecimento, seja ele experiencial, tradicional, ou científico e tecnológico, que possibilitará a construção de um saber ambiental que seja absorvido e aplicado por todos (LEFF, 2015).

Dessa forma, a educomunicação sob o enfoque da gestão comunicativa nos espaços educativos busca criar e rever as relações de comunicação na escola, entre direção, professores, alunos, bem como da escola com a comunidade, criando e fortalecendo ecossistemas comunicativos (SOARES, 2004b), que abrangem um entorno educacional difuso de informações, linguagens e saberes, descentrado da relação escola/livro, centrais no sistema educativo atual (MARTÍN-BARBERO, 2001, apud ALVES, 2007).

Dito isto, este trabalho objetiva descrever a educomunicação como estratégia de socialização dos saberes ambientais construídos mediante relação entre escola e comunidade, inserida em um processo mais amplo e sistêmico da pedagogia ambiental. Trata-se de uma pesquisa do tipo bibliográfica, tomando por base materiais já elaborados, principalmente livros e revistas científicas.

$\mathrm{O}$ artigo está divido em duas partes, a saber: a primeira busca discutir a interrelação dos campos da Educação e da Comunicação a partir da evolução do conceito de 
educomunicação na América Latina; a segunda, busca situar a educomunicação no processo de construção de uma pedagogia ambiental pautada no diálogo de saberes e na interdisciplinaridade, elegendo a comunidade do entorno imediato à escola, um campo de intervenção adequado para a investigação da problemática socioambiental, e oferecendo pistas para a construção de um ecossistema comunicativo pautado numa proposta pedagógica ancorada nas questões socioambientais.

\section{Educomunicação: um conceito em construção}

A educomunicação tem sua origem no diálogo entre Comunicação popular e Educação popular. Estes dois campos de intervenção ${ }^{5}$ irão respaldar a proposta educomunicativa na América Latina a partir dos anos 60, em um contexto de lutas contra os regimes totalitários que foram se instalando na região e que refletiam diretamente no cerceamento dos direitos civis, especialmente na comunicação social com restrições à liberdade de expressão, tanto na esfera individual quanto na coletiva (MARQUES; TALARICO, 2016).

As ações desenvolvidas no âmbito dos movimentos de comunicação popular, organizadas em sua maioria por Organizações Não Governamentais (ONGs) e outras entidades do terceiro setor, tinham como objetivo aguçar a criticidade dos envolvidos frente às mensagens emitidas pelos meios massivos de comunicação (SOARES, 2011), os quais, além de não pautar questões relacionadas à cidadania, tinham sua programação submetida ao crivo dos órgãos censores da ditadura civil-militar, podendo esta ser censurada caso o conteúdo "[...] fosse considerado como inadequado aos valores políticos, aos interesses econômicos e/ou à moralidade vigente" (MARQUES; TALARICO, 2016, p. 425).

Diante da ausência de uma pauta cidadã nos meios de comunicação de massa, os movimentos de comunicação popular se organizaram para desenvolver o processo educomunicativo em comunidades rurais, urbanas, indígenas, e outras, na tentativa de promover a expressão daqueles, cujas vozes são invisibilizadas nos meios hegemônicos de comunicação. Assim, passa a existir uma comunicação alternativa a serviço dos interesses da classe trabalhadora (PERUZZO, 1998). Ainda de acordo com Peruzzo (2009), as iniciativas de comunicação popular, e conceitos congêneres, possuem o mesmo sentido

\footnotetext{
${ }^{5}$ São considerados campos de intervenção, no sentido bourdieusiano, pois estavam comprometidos com a transformação social, mediante práticas dos movimentos sociais e Organizações Não Governamentais, não sendo uma teoria sistematizada e referenciada no campo acadêmico.
} 
político de constituir uma forma de mobilização e expressão das classes subalternas da população, tendo em vista estabelecer a justiça social mediante participação política.

Os processos comunicacionais identificados em países da América Latina, como Argentina, Chile, Cuba, Uruguai, Venezuela e Brasil, a partir da década de 1960, revelaram diversas experiências desenvolvidas pelos chamados comunicadores populares, um ofício forjado na militância dos movimentos sociais, mediante oficinas, seminários e encontros, cuja pretensão não era utilizar-se dos meios hegemônicos, mas contribuir com a formação da comunidade, a partir da construção de um processo comunicativo comum a todos, pautado no diálogo, capacidade de expressão e direito à comunicação (SOARES, 2002).

$\mathrm{O}$ aspecto inter-relacional entre educação e comunicação tem como precursor na América Latina, na década de 1960, o educador Paulo Freire, para o qual a educação é um ato dialógico, sendo o conhecimento um produto da relação entre os seres humanos e destes com o mundo. Este pensamento é sintetizado em uma das frases mais célebres do educador:"[...] ninguém educa ninguém, ninguém educa a si mesmo, os homens se educam entre si, mediatizados pelo mundo" (FREIRE, 2002, p. 68). Assim, Freire (1982) considera que o diálogo é a forma mais segura para a educação e a libertação de todos os homens e todas as mulheres, opressores e oprimidos.

Ao construir as bases de uma educação popular, Paulo Freire insere uma orientação política, social e cultural, elaborada como Pedagogia do Oprimido, defendendo uma educação libertadora, pautada no princípio da contradição como geradora de consciência, em que o oprimido vê-se subjugado por outros, e o opressor se reconhece como tal. A educação libertadora é um processo que privilegia a dialogicidade em detrimento da educação "bancária" (instrumento de opressão), privilegia a humanização em detrimento da alienação (FREIRE, 2002).

O fato é que a Pedagogia do Oprimido de Paulo Freire inspirou vários estudos latino-americanos sobre comunicação popular, incorporando a corrente que pressupõe a comunicação dialógica e libertadora como alternativa ao modelo linear vigente, composto por três elementos essenciais: emissor, mensagem, receptor (COGO, 1994). O pensamento freireano inspirou os estudos do argentino Mário Kaplún (1923-1998) e do paraguaio Juan Diaz Bordenave (1926-2012) na construção dos conceitos de comunicação participativa e comunicação popular, como propostas comunicativas que conseguiram aproximar os campos da comunicação, educação e cultura. 
A participação e o diálogo são princípios perseguidos pelas propostas de Kaplún e Diaz Bordenave, considerando-os determinantes tanto para a prática da comunicação popular, quanto para a educação libertadora. Para Diaz Bordenave (1983), na comunicação participativa ou participatória, todos os interlocutores exercem livremente seu direito à autoexpressão, trocando seus próprios temas e mensagens, criando conhecimentos e saberes de forma solidária, adquirindo poder coletivo, buscando a solução dos problemas comuns e, assim, contribuindo para a transformação permanente e inalienável da sociedade (DIAZ BORDENAVE, 1983). Ainda segundo o autor, a situação de liberdade é prerrogativa fundamental para que a comunicação aconteça. Assim, nos processos centrados em situações de opressão, decorre-se uma situação de "não-comunicação" ou “incomunicação".

Tendo como base a obra "Pedagogia do Oprimido" de Paulo Freire, Diaz Bordenave (1983) identificou e analisou de forma crítica três concepções de educação, duas exógenas e uma endógena: a) Educação com ênfase nos conteúdos (concepção exógena) - prioriza a transmissão de conhecimentos, é descrita por Paulo Freire como educação "bancária", por envolver "[...] o ato de depositar, de transferir, de transmitir valores e conhecimentos [...]" (FREIRE, 2002, p.59); b) Educação com ênfase nos efeitos (concepção exógena) - atua diretamente no comportamento humano, induzindo à "participação" dos educandos na execução das atividades que foram planejadas sem sua participação, mirando resultados de produtividade em detrimento da reflexão crítica; c) Educação com ênfase no processo (concepção endógena) - a ênfase está no processo de transformação do indivíduo e sua realidade social a partir da criação de dispositivos que permitam o desenvolvimento de suas capacidades intelectuais e sua consciência social.

Ao retomar os escritos de Juan Diaz Bordenave sobre as concepções de educação, Mário Kaplún contribui significativamente para o entendimento da educação na prática da comunicação. Para Kaplún (2002, apud BRASIL, 2010) cada paradigma de educação possui uma concepção e uma prática correspondente na comunicação. Assim, para a concepção de educação com ênfase no conteúdo, sistematizada na transmissão de conhecimento ou educação "bancária", existe também uma comunicação "bancária" baseada no mesmo preceito: a transmissão de informação de forma unidirecional, sempre no sentido emissor-receptor. Para a concepção de educação com ênfase nos efeitos, que consiste em moldar o comportamento das pessoas para se atingir algum objetivo preestabelecido, Kaplún designa uma “comunicação persuasiva”, na qual o receptor emite 
uma resposta estereotipada, considerada adequada apenas quando atende ao interesse do emissor.

Porém, é na concepção de educação com ênfase no processo, fundamentada no modelo de educação libertadora proposta por Paulo Freire, que Kaplún assenta as bases da comunicação popular. Kaplún (2002, apud BRASIL, 2010) defende uma comunicação popular centrada no processo, baseada em uma proposta educativa que, ao estimular a participação ativa do sujeito no processo, obtenha resultados formativos. A proposta processual de educação, portanto, foca no "aprender a aprender", ou seja, em como os sujeitos aprendem, de modo que esta aprendizagem possibilite a consciência crítica de si enquanto sujeito, do outro, e de sua realidade social. Assim, a "[...] aprendizagem ocorre no vivido, no que é recriado, no que se reinventa e não somente no que se lê e se escuta, [...] a aprendizagem somente ocorre quando é processual e quando também há gestão dos educandos" (KAPLÚN, 2002, apud BRASIL, 2010, p. 14).

Um importante avanço no sentido da inter-relação entre comunicação e educação é atribuído à pesquisa coordenada pelo Professor Ismar de Oliveira Soares, entre 1997 e 1998, no âmbito do Núcleo de Comunicação e Educação (NCE) da Escola de Comunicações e Artes (ECA) na Universidade de São Paulo (USP), com participação de 178 especialistas (produtores culturais, arte-educadores, tecnólogos, professores, pesquisadores e profissionais de comunicação e educação) de 12 países da América Latina (CORTES; MARTINS; SOUZA, 2018).

A pesquisa intitulada "Inter-relações entre comunicação e educação na cultura latino-americana" identificou as práticas aportadas na interface comunicação e educação, reconhecendo as atividades desenvolvidas por comunicadores populares, que passa a ser denominado educomunicador, e sistematizando tais práticas em uma nova área de intervenção social denominada educomunicação. Assim, o campo da educomunicação não emerge da academia, mas dos movimentos sociais (BRASIL, 2008).

Embora a América Latina tenha dado uma contribuição mais expressiva às práticas educomunicativas, é importante esclarecer que este campo de intervenção já havia sido identificado e analisado na Europa e nos Estados Unidos. No início do século XX, as discussões em torno da interface educação e comunicação, nos Estados Unidos, estavam compreendidas em um campo denominado media literacy, que tinha como foco uma educação para uma leitura crítica dos meios de comunicação, preocupando-se com o poder de influência da mídia na vida de crianças e adolescentes. Ainda nos Estados Unidos, na década de 1930, essa discussão provocou o surgimento de outro campo denominado 
infomation litercy, a partir do qual propunha-se a mediação tecnológica nos espaços educativos, como instrumento de inovação e criatividade no processo de ensinoaprendizagem (SOARES, 2002).

As fases da inter-relação comunicação/educação nos Estados Unidos apresentadas por Soares (2002), suscitaram diversas abordagens e influenciaram teorias e práticas ao longo do século XX. No campo de estudos denominado de media litercy, o autor identifica o domínio de três fases em períodos distintos: a fase defensiva (deficit model), nos anos 70, que como o próprio nome já diz, adotou uma postura defensiva diante dos meios de comunicação em massa, sobretudo a televisão, responsabilizando-os pelos efeitos negativos para o comportamento de crianças e adolescentes; a fase de desautorização, nos anos 80, assim denominada pela redução significativa de recursos para pesquisas em relação à influência da mídia massiva na problemática social, adotando uma postura mais tolerante; e a fase de recuperação ou retomada, a partir dos ano 90, caracterizada pela busca de instruir os estudantes a fazerem uma leitura crítica das mensagens produzidas nos meios de comunicação, bem como a desenvolverem experiências na área, produzindo suas próprias mensagens.

Na América Latina, estas tendências de educomunicação (educação para uma leitura crítica da mídia e mediação tecnológica para a educação) também foram identificadas, contudo, inseridas nos movimentos de comunicação popular. Porém, outra tendência aparece de forma recorrente: a gestão comunicativa para o campo pedagógico. De acordo com Cortes, Martins e Souza (2018, p. 12), a gestão da comunicação em espaços educativos “[...] compreende o planejamento e a execução de políticas de comunicação educativa, buscando unir ações comunicativas para ampliar os espaços de expressão".

Sobre esta tendência, Soares (2002) defende que a gestão da comunicação nos espaços educativos é que garante a coordenação e eficiência da 'educação para a comunicação' e da 'mediação tecnológica para educação', cuja integração destes campos ao cotidiano escolar é fundamental para a visibilidade das ações comunicativas de professores, alunos, e toda comunidade escolar, possibilitando criar e fortalecer ecossistemas comunicativos.

A expressão "ecossistema comunicativo" foi designada pelo filósofo espanocolombiano Jésus Martín-Barbero em alusão ao conceito biológico de ecossistema, segundo o qual, “[...] as comunicações entre os agentes, que interferem em determinado ambiente, estão todas interligadas, como nas teias alimentares, e são fundamentais para a 
manutenção da vida naquele ambiente; há ecossistemas mais ricos, outros mais pobres" (MARTÍN-BARBERO, 2008, apud BRASIL, 2010, p. 22). Contudo, a expressão foi empregada em relação a mediação tecnológica nos processos comunicacionais da sociedade da informação, em que a apropriação tecnológica passaria de uma condição instrumental para estrutural, formando um ecossistema comunicativo (SOARES, 2014).

Nas pesquisas sobre educomunicação desenvolvidas pelo NCE-ECA/USP, o conceito de ecossistema comunicativo foi ampliado, considerando "[...] o relacionamento entre seres humanos num dado espaço, independentemente do uso dos recursos tecnológicos" (SOARES, 2013, p. 185). Desse modo, a gestão da comunicação em espaços educativos busca garantir que a mediação tecnológica na educação não seja reduzida ao aparelhamento das escolas e salas de aulas com novas Tecnologias de Informação e Comunicação (TIC) como instrumentos performáticos apenas para professores continuarem reproduzindo o modelo tradicional de ensino baseado na comunicação linear: professor - emissor, e aluno - receptor. O entendimento em relação ao ambiente mediado por tecnologias, é que este "[...] pode ajudar a produzir sentidos, convertendo-se em mediação. É o sentido que provoca a aprendizagem, não a tecnologia, e é por isso que o campo compete à comunicação ou à educomunicação" (SOARES, 2002, p. 20).

Contudo, a educomunicação não está centrada em sujeitos ou lugares determinados, mas no processo educativo, a cargo de um educomunicador, responsável por planejar, coordenar, implantar e avaliar atividades pedagógicas que relacionam as interfaces comunicação/educação, considerando a mediação pelas tecnologias das relações humanas, para desenvolver diálogo e pluralismo (SOARES, 2014). Assim, Soares entende a educomunicação como sendo:

[...] o conjunto das ações inerentes ao planejamento, implementação e avaliação de processos, programas e produtos destinados a criar e a fortalecer ecossistemas comunicativos em espaços educativos presenciais ou virtuais, assim a como melhorar o coeficiente comunicativo das ações educativas, incluindo as relacionadas ao uso dos recursos da informação no processo de aprendizagem (SOARES, 2002, p. 24).

É importante pensar a educação pelo prisma da 'gestão dos processos de comunicação', pois a comunicação e o diálogo estão na essência do ato de ensinar e aprender (CORTES; MARTINS; SOUZA, 2018). Diante desse quadro de inserção das tecnologias na educação, o docente precisa incorporar em suas práticas pedagógicas essa nova forma de cultura e de saber que já faz parte do cotidiano de crianças e jovens, e que 
estão a moldar a identidade dessa geração, de modo a auxiliá-los no desenvolvimento de atitudes críticas em relação a elas, sem se deixarem manipular.

\section{Diálogo de saberes para uma Pedagogia Ambiental: o papel da educomunicação}

O reconhecimento da existência de uma crise ambiental ${ }^{6}$ na contemporaneidade vem sendo atribuído à consumação da separação entre cultura e natureza na conformação ambiciosa da modernidade, pois considera-se que o conhecimento técnico-científico, produzido em grande escala dentro da lógica de produção industrial, potencializou o poder de atuação humana sobre a natureza provocando efeitos danosos para ambos. Nessa perspectiva, a crise socioambiental evidencia a crise da construção do conhecimento, à medida em que reclama saídas eficazes para os problemas atuais da humanidade, e cujas respostas, produzidas a partir da mesma lógica instrumental em que os problemas foram e são criados, têm sido incapazes de abordar de forma adequada, questões mais abrangentes da contemporaneidade.

Diante dessa problemática, a ciência contemporânea tem apontado a fragmentação do conhecimento, instituída pelo paradigma ${ }^{7}$ moderno, como causadora da simplificação da realidade em campos disciplinares isolados. Japiassu (1972), considera que, quanto mais se desenvolvem e se diversificam as disciplinas, mais estas se distanciam da realidade humana. Assim sendo, a crise ambiental desafia o paradigma dominante ao demandar "[...] novas metodologias capazes de orientar um processo de reconstrução do saber que permita realizar uma análise integrada da realidade" (LEFF, 2002, p. 60).

Neste sentido, o paradigma que constitui e é constituída a ciência moderna tem apresentado um conhecimento superespecializado da realidade, priorizando o conhecimento das partes em detrimento de suas inter-relações com o todo, como defende Morin (1991) ao introduzir a noção de complexidade e dos sistemas complexos de fenômenos e saberes, como crítica à especialização e a tecnoburocracia. Assim, os conhecimentos dispostos de forma fragmentada "[...] não conseguem conjugar-se para alimentar um pensamento capaz de considerar a situação humana no âmago da vida, na

\footnotetext{
${ }^{6} \mathrm{~A}$ crise ambiental se apresenta na enorme quantidade de danos precisos, de poluições localizadas, de perigos identificados, mas também catástrofes exemplares (Bhopal, Chernobyl) e mesmo a provável ameaça que paira sobre os nossos recursos (erosão da biodiversidade biológica, desmatamento das regiões tropicais) ou sobre a nossa vida (buraco na camada de ozônio, efeito de estufa, etc.) (LARRÈRE; LARRÈRE, 1997).

${ }^{7} \mathrm{O}$ termo "paradigma" foi inicialmente associado por Thomas Kuhn à "ciência normal" e disciplinas específicas, sendo considerado como "[...] as realizações científicas universalmente reconhecidas que, durante algum tempo, fornecem problemas e soluções modelares para uma comunidade de praticantes de uma ciência" (KUHN, 2009, p.13).
}

Rev. Eletrônica Mestr. Educ. Ambient. Rio Grande, v. 37, n. 1, p. 89-108, jan/abr. 2020.

E-ISSN 1517-1256 
terra, no mundo, e de enfrentar os grandes desafios de nossa época" (MORIN, 2003, p. 1617).

Contudo, o isolamento do conhecimento não ocorre apenas entre as disciplinas científicas, mas também entre a ciência e os saberes não-científicos, o que tem sido apontado como fator limitador para a compreensão da realidade complexa. Neste sentido, Santos (1989) esclarece que "[...] deixou de ter sentido criar um conhecimento novo e autônomo em confronto com o senso comum se esse conhecimento não se destinar a transformar o senso comum e a transformar-se nele" (SANTOS, 1989, p.147). A propósito, o entendimento do sociólogo português a esse respeito é de que a acumulação de conhecimento sobre o mundo dado pelo desenvolvimento científico dos últimos três séculos, se resume a pouca sabedoria do mundo, do homem consigo próprio, com os outros, e com a natureza.

A ciência contemporânea tem se empenhado em discutir como construir um conhecimento científico pautado na diversidade e na multidimensionalidade das relações cultura e natureza, que seja capaz de fazer interagir os campos do saber, e considerar as diversas epistemologias produzidas e reivindicadas a partir das perspectivas dos próprios grupos sociais, sem cair no julgamento e redução imposta por uma narrativa onipotente (VASCONCELOS, 2002). Não há ainda respostas precisas para esta questão, porém o debate tem se dado em torno dos conceitos de pós-modernismo, complexidade, e interdisciplinaridade. Estas abordagens teóricas são responsáveis por transformações nas estruturas do saber, o que assegura o caráter inovador do espírito científico contemporâneo, como enaltece Bachelard (1978).

Contudo, essa novidade científica inaugura a necessidade de produzir sistematizações mais operativas no plano metodológico, que possam subsidiar a pesquisa, ensino e extensão, bem como a inter-relação entre o conhecimento científico produzido, propostas de ensino adequadas e socialização dos saberes.

\section{O saber ambiental como base para uma nova proposta pedagógica}

A crise ambiental em escala micro ou macrossocial tem suscitado na humanidade o sentimento de que é urgente e necessário repensar a sua relação com a natureza no tocante aos processos de exploração, produção e consumo, o que requer a assimilação de novos saberes ambientais (DANTAS, 2017). A ideia de um saber ambiental não está circunscrita 
e conformada nos paradigmas científicos, que são sistematizados em conteúdos disciplinares que compõem cursos e programas de formação ecológica. O saber ambiental, para além disso, extrapola a extensão paradigmática que instrumentaliza a produção do conhecimento nas ciências ambientais, e se apresenta como "[...] um campo de conhecimentos teóricos e práticos orientados para rearticulação das relações sociedadenatureza" abrindo-se ao "[...] terreno dos valores éticos, dos conhecimentos práticos e dos saberes tradicionais" (LEFF, 2015, p. 145).

Porém, Leff (2015) reconhece o caráter embrionário que ora se encontra este pensamento, necessitando ainda uma legitimação ideológica, teorias concretas e objetivação prática, o que não é algo fácil se considerarmos que o saber ambiental é um saber complexo, forjado na própria complexidade dos problemas socioambientais. Neste sentido, Leff acrescenta que:

[...] o saber ambiental é, pois, gerado num processo de conscientização, de produção teórica e de pesquisa científica. O processo educativo permite repensar e reelaborar o saber, na medida em que se transformam as práticas pedagógicas correntes de transmissão e assimilação do saber preestabelecido e fixado em conteúdos curriculares e nas práticas de ensino (LEFF, 2015, p. 152).

Deste modo, o saber ambiental se constrói mediante assimilação dos temas que emergem dos movimentos sociais, políticos e culturais, e que reclamam transformações nos paradigmas do conhecimento. Isso significa dizer, que o conhecimento e as práticas culturais de um povo em relação ao meio ambiente, patrimônio histórico que os definem como sujeitos, poderão dar origem a um produto teórico e científico, o qual deverá retornar como conhecimento sistematizado e fixado nos currículos e práticas de ensino (LEFF, 2015). Para o autor, os homens e as mulheres só existem por meio da cultura, apreendida mediante sentido e significado que é atribuído simbolicamente à matéria (LEFF, 2009).

As mudanças provocadas por um processo de conscientização de um saber ambiental, repercutidas numa nova racionalidade ambiental, implicaria em novos movimentos/transformações sociais, culturais, políticas e econômicas. Não obstante, essa problemática tem repercutido diretamente tanto nos processos de construção quanto de socialização de conhecimentos, devido à necessidade de internalização de novos saberes sobre a questão ambiental, que possibilitem uma visão integrada do meio ambiente.

Neste contexto, é prudente a implementação de uma pedagogia pautada nas questões socioambientais que favoreça a reflexão sobre os saberes, as práticas e técnicas 
pelas quais o sujeito e a comunidade se relaciona com o meio. Contudo, essa proposta suscita uma articulação entre escola e comunidade, de modo a permitir um intercâmbio na construção de saberes e tecer mecanismos de socialização.

\section{A educomunicação no processo de construção de um ecossistema comunicativo entre escola e comunidade}

O desafio de construir uma pedagogia ambiental ancorada nos novos paradigmas da complexidade e da interdisciplinaridade, suscita uma abordagem que trate a problemática socioambiental não apenas no contexto da relação sociedade e natureza, mas especialmente no contexto das relações entre os próprios seres humanos, mediante informações, linguagens e saberes mediadas ou não pelas novas tecnologias, tendo em vista a criação e fortalecimento de ecossistemas comunicativos.

Sem entrar na expressiva discussão já desenvolvida no campo das ciências sociais em torno do conceito de comunidade, utilizo-o no sentido de espaço analítico onde as escolas estão inseridas e exercem centralidades, e por considerar a comunidade um campo de intervenção privilegiado para pensar criticamente a realidade, em escala micro e macrossocial, e construir soluções para as diferentes problemáticas da atualidade, inclusive a problemática socioambiental.

Para Freire (1995) a prática educativa crítica é uma dimensão essencial da prática social, podendo estar alicerçada e/ou vinculada à participação comunitária. $\mathrm{O}$ conceito de participação empregado aqui, segue o entendimento de Diaz Bordenave (1994), para o qual "a participação é uma habilidade que se aprende e se aperfeiçoa. Isto é, as diversas forças e operações que constituem a dinâmica da participação devem ser compreendidas e dominadas pelas pessoas" (DIAZ BORDENAVE, 1994, p. 47).

Neste sentido, não há como desenvolver uma pedagogia adequada à problemática socioambiental pautada apenas na aplicação de saberes produzidos em tempos e espaços distantes da ação pedagógica. Portanto, faz-se imperativa uma proposta tecida na própria reflexão/ação intencional dos docentes a partir do julgamento que fazem a respeito do contexto socioambiental mediante repertório de saberes que dispõem, construídos na interrelação com os demais agentes sociais ${ }^{8}$.

Considerando os esforços empregados nas últimas décadas para mitigar os problemas socioambientais decorrentes da relação desequilibrada entre sociedade e

\footnotetext{
${ }^{8}$ Consideramos como agentes sociais envolvidos no processo educativo, a família, a escola e outras instituições públicas,
} as empresas, os meios de comunicação, que atuam no âmbito de uma coletividade/comunidade. 
natureza, que tem sua origem no modelo de racionalidade predominantemente econômica, o campo da educomunicação sugere a criação e fortalecimento de 'ecossistemas comunicativos' nos espaços educativos, ampliando o fluxo das relações entre as pessoas e os grupos humanos, mediadas pelo uso adequado das tecnologias da informação (SOARES, 2004a).

Porém, a comunicação na educação não se reduz a um instrumento midiático e tecnológico, ela é um importante componente pedagógico em vias da interdisciplinaridade, no qual "convergem uma leitura da Pedagogia a partir da comunicação e uma leitura da comunicação a partir da Pedagogia" (KAPLÚN, 1999, apud MARQUES; TALARICO, 2016, p. 428). Uma atitude mediadora é uma atitude interdisciplinar, pois os agentes envolvidos no processo comunicativo consideram válidos os conhecimentos advindos das outras pessoas, das outras áreas ou disciplinas. Assim, a interdisciplinaridade é uma das principais características da educomunicação, não como categoria de conhecimento, mas como categoria de ação, desenvolvida a partir da relação das próprias disciplinas (FAZENDA, 2008).

Inserir a educomunicação como estratégia de criação e fortalecimento de ecossistemas comunicativos, requer uma verdadeira 'gestão da comunicação nos espaços educativos' presenciais. Este é um processo que requer flexibilidade no planejamento das ações, devendo-se considerar as adaptações demandadas pela própria dinâmica das ações e do grupo, e o contexto da aplicação. Assim, não sendo possível apresentar um modelo fixo de plano de ação, com a descrição detalhada das etapas, apresentamos alguns procedimentos essenciais para o desenvolvimento de propostas de educomunicação na perspectiva da pedagogia ambiental, a saber:

a) Planejamento das ações - as ações educomunicativas devem pautar-se pela intencionalidade e compromisso com a melhoria do processo pedagógico. Para tanto, é fundamental que a comunidade escolar defina e implemente a educomunicação como estratégia prevista em seu Projeto Político Pedagógico (PPP), de modo a evitar ações isoladas e comprometidas com a educação tradicional e as práticas autoritárias de comunicação.

O planejamento deve partir de uma problemática passiva de uma ação educomunicativa, a partir da qual são definidos os objetivos, justificativa, metodologias, recursos tecnológicos, cronograma, e as responsabilidades de cada agente que conduzirá o processo educomunicativo (docentes e discentes). 
b) Participação - ancora-se na concepção de gestão democrática em que a comunidade escolar (docentes, discentes, funcionários da escola, membros da comunidade) participa do planejamento, execução e avaliação das ações educomunicativas. As problemáticas a serem abordadas devem emergir da própria diversidade dos indivíduos que compõem a comunidade escolar e da diversidade dos ambientes onde estão inseridos (a escola e seu entorno), por meio de mecanismos de investigação.

Assim, tendo em vista à pedagogia ambiental, cabe investigar quais problemáticas emergem da percepção dos indivíduos sobre o ambiente onde vivem, considerando a diversidade socioeconômica, histórica e cultural.

c) Comunicação educativa processual - as ações educomunicativas devem priorizar o diálogo acerca de uma problemática levantada, de forma que os indivíduos envolvidos no processo desenvolvam uma consciência crítica acerca dos impactos destas problemáticas sobre suas vidas e sobre a coletividade. A comunicação educativa favorecerá o surgimento de ambientes democráticos pautado na dialogicidade e reflexão em torno dos problemas com elevado interesse pedagógico, evitando uma comunicação vertical e autoritária.

A pedagogia ambiental considera a diversidade dos saberes empíricos, construídos na relação do indivíduo com o ambiente, como parte da solução para o enfretamento da problemática socioambiental que ora se apresenta complexa. Neste contexto, a função do processo educomunicativo é visibilizar estes saberes por meio do diálogo/interação entre os diferentes indivíduos imbricados no processo, podendo potencializar estes saberes mediante uso das tecnologias de informação e comunicação.

d) Capacidade de expressão - o processo educomunicativo deve garantir ao indivíduo e à coletividade, a ampliação da capacidade de expressão, considerando a liberdade do pensamento forjado na diversidade histórica e cultural, e assegurando o direito à comunicação, mediada ou não pelas tecnologias de informação e comunicação. Neste sentido, deve-se observar a dimensão ética do processo comunicativo.

Considerando a pedagogia ambiental, as ações educomunicativas devem conduzir os indivíduos imbricados no processo, a refletirem sobre a melhor maneira de comunicar as problemáticas elencadas, bem como as possíveis soluções, de modo a atingir o conjunto da sociedade da qual fazem parte. 
e) Avaliação do processo educomunicativo - a avaliação permite identificar as potencialidades e fragilidades do processo educomunicativo, possibilitando aos indivíduos envolvidos uma reflexão sobre o fazer e o saber produzido. A avaliação deve ser feita em consonância entre os agentes que conduziram o processo educomunicativo (discentes e docentes) e os demais indivíduos participantes da comunidade, de modo que haja uma validação das etapas do processo, e do conteúdo produzido e disseminado nos meios de comunicação escolhidos.

Deste modo, as ações pedagógicas que introduzem as questões ambientais por intermédio da educomunicação devem considerar as condições específicas que caracterizam os diferentes ambientes, e a capacidade de estabelecer uma gestão educativa da comunicação que oriente os diversos indivíduos que atuam em um determinado espaço educativo. Por ser um campo que está sempre, e necessariamente, em construção, o aperfeiçoamento do ecossistema comunicativo dependerá da forma como o tema é introduzido (SOARES, 2004a), e do nível de relacionamento entre os indivíduos que integram a comunidade escolar, tendo as tecnologias de informação e comunicação a favor deste processo participativo, dialógico e reflexivo em torno de temas de elevado interesse pedagógico.

\section{Considerações Finais}

Os diversos problemas da sociedade contemporânea têm sobrecarregado a escola e a pedagogia na busca de alternativas didático-pedagógicas que solucionem os problemas produzidos e acumulados até aqui. O pensamento simplista de que a escola, esta ou aquela pedagogia solucionará os problemas da sociedade, desconsidera que a escola é o lugar onde atravessam todos os desafios contemporâneos da sociedade, porque a escola é a própria sociedade que se institucionaliza. Contudo, a escola é o lugar propício para investigar, problematizar, refletir e conscientizar sobre os problemas contemporâneos. E é neste mote que cabe a reorientação de modelos pedagógicos, e estratégias metodológicas que possibilitem uma melhor comunicação dos problemas sociais e ambientais em escala micro ou macrossocial.

O foco da educomunicação não está nas pessoas, no ambiente, ou no uso das tecnologias de informação e comunicação, mas no processo educativo da comunicação. Neste processo, as relações de comunicação estabelecidas entre as pessoas, em um 
determinado ambiente, mediadas pelo uso das tecnologias, em maior ou menor intensidade, podem constituir um ecossistema comunicativo, cujo fortalecimento dependerá da capacidade da gestão comunicativa.

A pedagogia ambiental parte do princípio de que os processos educativos devem abranger a complexidade da problemática socioambiental, em maior ou menor escala, e dentro de uma perspectiva interdisciplinar promover a aproximação entre os saberes científicos e tradicionais, considerando que em cada ambiente existe um processo peculiar de apreensão da realidade-mundo pelos sujeitos, e que deste processo decorrem as perguntas e respostas para as diversas questões do cotidiano, forjando a aquisição de novos saberes, símbolos e linguagens.

A educomunicação na perspectiva da pedagogia ambiental pressupõe uma gestão da comunicação nos espaços educativos baseada nos seguintes procedimentos: planejamento das ações, participação, comunicação educativa processual, capacidade de expressão e avaliação do processo educomunicativo.

Portanto, a educomunicação situa-se como parte estratégica da pedagogia ambiental, pois constitui metodologia indispensável para o enredamento dos saberes oriundos da comunidade com os saberes escolares sistematizados, de modo que se reduza o distanciamento entre um e outro no processo de ensino-aprendizagem, construindo e fortalecendo um ecossistema comunicativo entre escola e comunidade.

\section{Agradecimento}

O presente trabalho foi realizado com apoio da Coordenação de Aperfeiçoamento de Pessoal de Nível Superior - Brasil (CAPES) - Código de Financiamento 001. Fundação de Apoio à Pesquisa e à Inovação Tecnológica do Estado de Sergipe - FAPITEC/SE.

\section{Referências}

ALVES, Patrícia Horta. Gênese teórica e prática da educomunicação. In: Anais do XXX Congresso Brasileiro de Ciências da Comunicação. Santos: INTERCOM, 2007. Disponível em: http://www.intercom.org.br/papers/nacionais/2007/resumos/R2403-1.pdf . Acesso em: 26 jun. 2019.

BACHELARD, Gaston. O novo espírito científico. Tradução de Roberto Francisco Kuhnen. São Paulo: Abril Cultural, 1978. 
BRASIL. Ministério da Educação. Secretaria de Educação Básica. Comunicação e Uso de Mídias. Caderno Pedagógico n. 9. Série cadernos pedagógicos do Programa Mais Educação. Brasília, 2010. Disponível em:

http://educacaointegral.mec.gov.br/images/pdf/pme/comunicacao_midias.pdf. Acesso em: 01 jul. 2019.

COGO, Denise Maria. Comunicação e Cultura de Resistência - uma retrospectiva. In: SOARES, Ismar de Oliveira. A Comunicação de Resistência no Movimento Popular ligado à Igreja Católica. Relatório CNPq, (1994).

CORTES, Tanisse Paes Bóvio Barcelos; MARTINS, Analice de Oliveira. SOUZA, Carlos Henrique Medeiros de. Educação midiática, educomunicação e formação docente: parâmetros dos últimos 20 anos de pesquisas nas bases SciELO e Scopus. Educação em Revista [online], vol.34, e200391, 2018. ISSN 0102-4698. Disponível em: http://dx.doi.org/10.1590/01024698200391. Acesso em: 26 jun. 2019.

DANTAS, Jonielton Oliveira. Saberes ambientais na profissionalização docente e sua operatividade na prática pedagógica. Dissertação (Mestrado em Desenvolvimento e Meio Ambiente). Universidade Federal de Sergipe - UFS. São Cristóvão: UFS, 2017. Disponível em: https://ri.ufs.br/bitstream/riufs/7855/2/JONIELTON OLIVEIRA DANTAS.pdf. Acesso em: 26 jun. 2019.

DIAZ BORDENAVE, Juan Enrique. Além dos Meios e Mensagens. Petrópolis: Ed. Vozes, 1983.

DIAZ BORDENAVE, Juan Enrique. O que é participação. 8. ed. São Paulo: Brasiliense, 1994.

FAZENDA, Ivani Catarina Arantes. Interdisciplinaridade: história, teoria e pesquisa. 15 ed. Campinas: Papirus, 2008.

FREIRE, Paulo. Extensão ou comunicação. Rio de Janeiro: Editora Paz e Terra, 1982.

FREIRE, Paulo. Política e educação. 2. ed. São Paulo: Cortez, 1995.

FREIRE, Paulo. Pedagogia do oprimido. 32.ed. Rio de Janeiro: Paz e Terra, 2002.

JAPIASSU, Hilton. Interdisciplinaridade e patologia do saber. Rio de Janeiro: Imago, 1972.

KUHN, Thomas Samuel. A Estrutura das revoluções científicas. Tradução Beatriz Vianna Boeira e Nelson Boeira. 10. ed. São Paulo: Perspectiva, 2009.

LARRÈRE, Catherine. LARRÈRE, Raphael. Do bom uso da natureza: para uma filosofia do meio ambiente. Tradução Armando Pereira da Silva. Lisboa: Ed. Instituto Piaget, 1997.

LEFF, Enrique. Complejidad, racionalidad ambiental y diálogo de saberes: hacia una pedagogia ambiental.V Congreso Iberoamericano de Educación Ambiental. Joinville, 
de 4 a 8 de abril de 2006. Disponível em: https://www.miteco.gob.es/es/ceneam/articulosde-opinion/2006_01eleff_tcm30-163650.pdf. Acesso em: 26 jun. 2019.

LEFF, Enrique. Cultura Ecológica e Racionalidade Ambiental. In: LEFF, Enrique.

Ecologia, capital e cultura: a territorialização da racionalidade ambiental. Petrópolis: Editora Vozes, 2009.

LEFF, Enrique. Epistemologia Ambiental. Tradução Sandra Valenzuela; revisão técnica de Paulo Freire Vieira.3. ed. São Paulo: Cortez, 2002.

LEFF, Enrique. Saber ambiental: sustentabilidade, racionalidade, complexidade, poder. 11. ed. Petrópolis: Editora Vozes, 2015.

MORIN, Edgar. A cabeça bem-feita: repensar a reforma, reformar o pensamento. Tradução Eloá Jacobina. 8. ed. Rio de Janeiro: Bertrand Brasil, 2003.

MORIN, Edgar. Introdução ao pensamento complexo. Lisboa: Instituto Piaget, 1991.

MÁRQUES, Fernanda Telles. TALARICO, Blueth Sabrina Lobo Uchôa. Da comunicação popular à educomunicação: reflexões no campo da "educação como cultura". Atos de Pesquisa em Educação. v. 11, n. 2, Blumenau, 2016. Disponível em: http://dx.doi.org/10.7867/1809-0354.2016v11n2p422-443. Acesso em: 26 jun. 2019.

PENTEADO, Heloísa Dupas. Meio ambiente e formação de professores. 6 ed. São Paulo: Cortez, 2007.

PERUZZO, Cecilia Maria Krohling. Comunicação nos movimentos populares: a participação na construção da cidadania. - Petrópolis, RJ: Vozes, 1998.

PERUZZO, Cecilia Maria Krohling. Conceitos de Comunicação popular, alternativa e comunitária revisitados. Reelaborações no setor. Palabra Clave, Bogotá, 11, jul. 2009. Disponível em:

http://palabraclave.unisabana.edu.co/index.php/palabraclave/article/view/1503/1744. Acesso em 24 jun. 2019.

SANTOS, Boaventura de Souza. Introdução a uma ciência pós-moderna. Rio de Janeiro: Graal, 1989.

SOARES, Ismar de Oliveira. Educomunicação: um campo de mediações. Comunicação \& Educação, n. 19, São Paulo, p. 12-24, 2000. Disponível em: https://doi.org/10.11606/issn.2316-9125.v0i19p12-24. Acesso em: 21 jun. 2019.

SOARES, Ismar de Oliveira. Ecossistemas comunicativos. Núcleo de Comunicação e Educação - USP, n. 28, 2004a. Texto [online]. Disponível em: http://www.usp.br/nce/wcp/arq/textos/28.pdf. Acesso em 30 jun. 2019.

SOARES, Ismar de Oliveira. Educomunicação: as múltiplas tradições de um campo emergente de intervenção social na Europa, Estados Unidos e América Latina. In: LIMA, João Claudio Garcia R. MELLO, José Marques de. (Orgs.). Panorama da Comunicação e das Telecomunicações no Brasil (2012/2013). Brasília: Ipea, 2013. 
SOARES, Ismar de Oliveira. Gestão comunicativa e educação: caminhos da educomunicação. Revista Comunicação \& Educação, n. 21, p. 16-25, 2002. Disponível em: http://www.revistas.usp.br/comueduc/article/view/37012. Acesso em: 02 jul. 2019.

SOARES, Ismar de Oliveira. Mas, afinal, o que é educomunicação? Núcleo de Comunicação e Educação - USP, n. 27, 2004b. Texto [online]. Disponível em: http://www.usp.br/nce/wcp/arq/textos/27.pdf. Acesso em 01 jul. 2019.

SOARES, Ismar de Oliveira. Educomunicação e a formação de professores no século XXI. Revista FGV Online. v. 4, n. 1, 2014. Disponível em:

http://bibliotecadigital.fgv.br/ojs/index.php/revfgvonline/article/view/41468/40212. Acesso em: 02 jul. 2019.

VASCONCELOS, Eduardo Mourão. Complexidade e pesquisa interdisciplinar: epistemologia e metodologia operativa. Petrópolis: Editora Vozes, 2002.

Submetido em: 28-09-2019.

Publicado em: 17-04-2020. 